\title{
DETERMINAÇÃO DE PROPRIEDADES DO ÓLEO RESIDUAL DE FRITURAS, COM E SEM FILTRAÇÃO, EM DIFERENTES TEMPERATURAS
}

\author{
M. SILVA ${ }^{1}$, M. SACARDO ${ }^{1}$, A. E. COSTA $^{1}$ e J. K. ANDREAZZA ${ }^{1}$ \\ ${ }^{1}$ Centro Universitário Tupy - UNISOCIESC, Departamento de Engenharia Química \\ E-mail para contato: mariane.silva.q@gmail.com
}

\begin{abstract}
RESUMO - O óleo residual de frituras é uma matéria-prima com grande potencial para emprego na síntese de biodiesel, visto que possui menor custo que os óleos virgens e seu aproveitamento reduz a ocorrência de descarte inadequado, o qual constitui um problema ambiental. Sendo assim, o presente estudo tem por objetivo determinar o perfil reológico e propriedades do óleo residual sujo e filtrado, tais como viscosidade dinâmica, massa específica e viscosidade cinemática, em diferentes temperaturas. $\mathrm{O}$ conhecimento de tais propriedades é importante para a aplicação deste material na síntese do biodiesel, uma vez que a qualidade do biodiesel produzido está relacionada com as características da matéria-prima oleaginosa utilizada em sua síntese, dentre outros fatores. Verificou-se que a massa específica, a viscosidade dinâmica e a viscosidade cinemática diminuem quando se eleva a temperatura, conforme esperado. Quanto ao perfil reológico do óleo residual tanto sujo como filtrado, constatou-se que na faixa de temperaturas estudada este comporta-se como um fluido dilatante, ou seja, sua viscosidade aparente aumenta com a taxa de deformação.
\end{abstract}

\section{INTRODUÇÃO}

Os óleos vegetais constituem parte da alimentação e seu consumo tende a aumentar movido pelo estilo de vida atual da sociedade. Quando utilizado no preparo de alimentos torna-se um resíduo que muitas vezes é descartado inadequadamente na rede de esgoto ou diretamente nos solos ou águas. A presença deste resíduo impermeabiliza o solo, na rede de esgoto dificulta o processo de tratamento, e quando descartado nas águas possui alta taxa de contaminação (Christoff, 2006). Segundo Bortoluzzi (2011), cada litro de óleo de cozinha é capaz de poluir aproximadamente um milhão de litros de água.

Uma forma de evitar que o óleo usado de cozinha agrida o meio ambiente é aproveitá-lo para produzir biodiesel. O biodiesel é um combustível constituído de ésteres de ácidos graxos de cadeia longa, ésteres alquila, derivados de óleos vegetais ou gorduras animais e sua produção pode ser considerada importante como alternativa energética (Gorren, 2009) 
Segundo Costa Filho (2008), durante o processo de fritura, devido à exposição à temperatura, há formação e absorção de compostos polares pelo óleo que retardam a reação de produção de biodiesel além de diminuir seu rendimento. Ocorrem também modificações físico-químicas pela interação do alimento com o meio, como a hidrólise, a qual aumenta o teor de ácidos graxos livres do óleo que, quando em valor superior a 3\% eleva o índice de saponificação e, consequentemente, a viscosidade do biodiesel (Costa Filho, 2008).

A viscosidade do óleo é influenciada pela presença de água em sua composição e pelo índice de ácidos graxos livres, visto que taxas mais altas elevam o índice de saponificação que interfere na viscosidade (Costa Filho, 2008). Por isso, analisar a viscosidade do óleo residual que será utilizado para produzir o biodiesel é de grande importância. O biodiesel é produzido através de transesterificação, para facilitá-la é necessário realizar pré-tratamento no óleo residual de frituras. Como cita Carrapato (2010) os processos de pré-tratamento do óleo residual são indispensáveis, já que nesse caso as características do óleo encontram-se quimicamente alteradas.

O óleo residual de frituras é um material sujeito a grande variabilidade quanto à sua composição e às suas propriedades, visto que suas características dependem de diversos fatores, como o modo como foi utilizado, o tempo de uso e as condições de armazenagem (Costa Filho, 2008). Assim, neste estudo serão determinadas as propriedades do óleo residual de frituras sujo e filtrado, que posteriormente será usado na produção de biodiesel.

\section{MATERIAIS E MÉTODOS}

Para a realização dos experimentos foram separados e identificados cinco béqueres, cada um contendo $500 \mathrm{~mL}$ de óleo residual de frituras. O óleo residual é de fonte residencial foi coletado na cidade de Joinville-SC, nos bairros Aventureiro e Espinheiros. Cada amostra foi aquecida e mantida a uma determinada temperatura $-20^{\circ} \mathrm{C}, 25^{\circ} \mathrm{C}, 30^{\circ} \mathrm{C}, 35^{\circ} \mathrm{C}$ ou $40^{\circ} \mathrm{C}-$ para a determinação de massa específica, viscosidade dinâmica e viscosidade cinemática. Após, o óleo foi filtrado e os experimentos conduzidos da mesma forma que para o óleo residual sujo. Todos os ensaios foram realizados em duplicata.

Para a determinação da massa específica do óleo, foram calibrados cinco picnômetros de $25 \mathrm{~mL}$, cada um em uma determinada temperatura $-20^{\circ} \mathrm{C}, 25^{\circ} \mathrm{C}, 30^{\circ} \mathrm{C}, 35^{\circ} \mathrm{C}$ ou $40^{\circ}$-, utilizando água deionizada e balança analítica. Após a calibração, a massa específica do óleo a diferentes temperaturas foi determinada pela Equação 1:

$$
\rho=m / V
$$


Para a determinação do comportamento reológico e viscosidade dinâmica do óleo em diferentes temperaturas utilizou-se um viscosímetro de Brookfield, nas velocidades de 10, 20, 50 e $100 \mathrm{rpm}$.

No viscosímetro utilizado obteve-se os valores de viscosidade dinâmica. Uma vez que a massa específica do óleo a diferentes temperaturas também foi determinada, podemos obter também os valores de viscosidade cinemática através da Equação 2:

$$
v=\mu / \rho
$$

\section{RESULTADOS E DISCUSSÃO}

Os resultados da determinação da massa específica do óleo a diferentes temperaturas por picnometria são apresentados na Tabela 1. Observa-se que a densidade do óleo residual, em ambos os casos, diminui moderadamente com o aumento da temperatura.

Tabela 1- Massa específica do óleo residual de frituras em diferentes temperaturas.

\begin{tabular}{cccc}
\hline Temperatura & $\begin{array}{c}\text { Volume do } \\
\text { picnômetro }(\mathrm{ml})\end{array}$ & $\begin{array}{c}\text { Massa específica } \\
\text { do óleo residual } \\
(\mathrm{g} / \mathrm{mL})\end{array}$ & $\begin{array}{c}\text { Massa específica } \\
\text { do óleo filtrado } \\
(\mathrm{g} / \mathrm{mL})\end{array}$ \\
\hline $20^{\circ} \mathrm{C}$ & 25,492 & 0,9199 & 0,9181 \\
$25{ }^{\circ} \mathrm{C}$ & 25,469 & 0,9178 & 0,9166 \\
$30^{\circ} \mathrm{C}$ & 25,494 & 0,9135 & 0,9135 \\
$35^{\circ} \mathrm{C}$ & 25,469 & 0,9118 & 0,9114 \\
$40^{\circ} \mathrm{C}$ & 25,589 & 0,9063 & 0,9051 \\
\hline
\end{tabular}

Após as determinações de massa específica, realizou-se a análise reológica do óleo residual sujo, a fim de definir qual o comportamento de sua viscosidade quando este é submetido a diferentes taxas de deformação, em diferentes temperaturas. Os resultados são apresentados na Figura 1. 
Figura 1 - Comportamento reológico do óleo residual sujo em diferentes temperaturas.

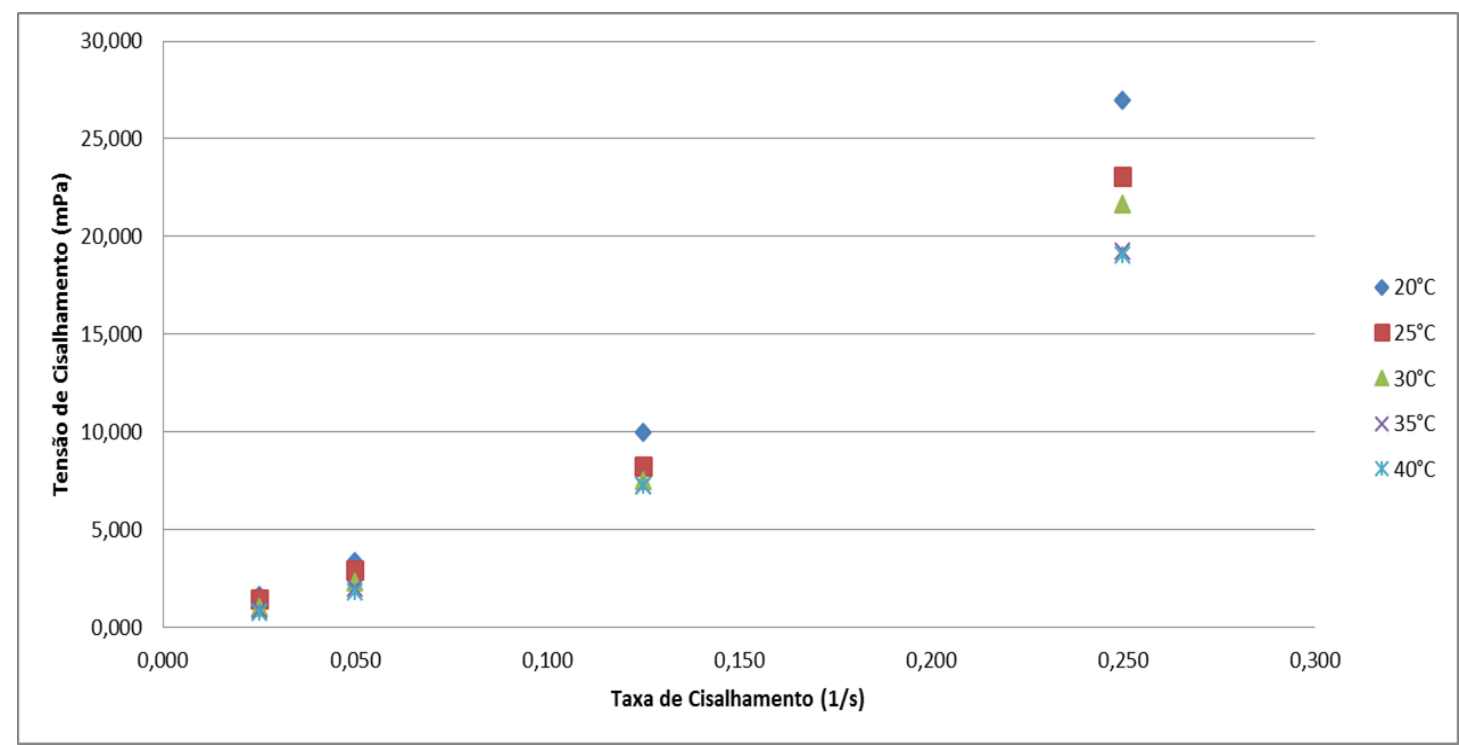

Para o óleo residual filtrado foi feita a mesma análise reológica, a fim de determinar o comportamento da viscosidade quando ele é submetido a diferentes taxas de deformação em algumas temperaturas. Conforme mostra a Figura 2.

Figura 2 - Comportamento reológico do óleo residual de filtrado em diferentes temperaturas.

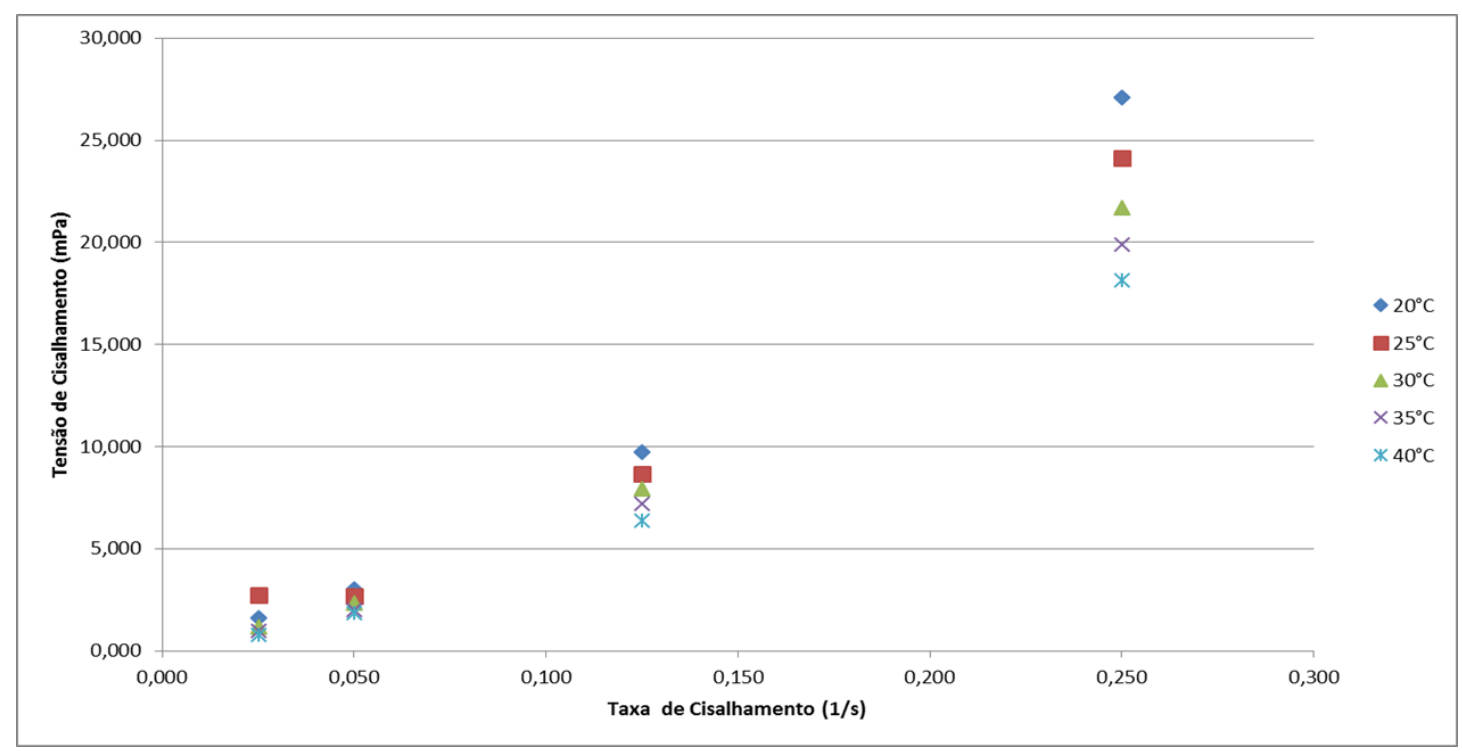

Na Figura 1 observa-se que em todas as temperaturas o óleo residual de frituras sujo comportou-se como um fluido dilatante, ou seja, sua viscosidade aparente aumenta com o aumento da taxa de deformação. No caso do óleo residual filtrado percebeu-se o mesmo 
comportamento, identificando-se assim que ele também se comporta como um fluido dilatante. É importante destacar que as viscosidades aparentes do óleo, sujo e filtrado, diminuíram com o aumento da temperatura, conforme esperado para líquidos.

$\mathrm{Na}$ Tabela 2 são apresentados os valores de viscosidade cinemática para o óleo residual sujo e para o óleo residual filtrado, calculados pela Equação 2. Como a viscosidade dinâmica dos óleos não mostraram-se constantes com a taxa de deformação, usou-se como referência a velocidade de $20 \mathrm{rpm}$.

Tabela 2- Viscosidade cinemática do óleo sujo e óleo filtrado a diferentes temperaturas.

\begin{tabular}{ccccc}
\cline { 2 - 5 } Temperatura $\left({ }^{\circ} \mathrm{C}\right)$ & $\mu(\mathrm{cP})$ & $v\left(\mathrm{~mm}^{2} / \mathrm{s}\right)$ & $\mu(\mathrm{cP})$ & $v\left(\mathrm{~mm}^{2} / \mathrm{s}\right)$ \\
\cline { 2 - 5 } & 67,5 & 73,37 & 60,5 & 65,90 \\
25 & 59,0 & 64,29 & 54,0 & 58,91 \\
30 & 47,0 & 51,45 & 46,5 & 50,90 \\
35 & 40,0 & 43,87 & 40,0 & 43,89 \\
40 & 37,0 & 40,83 & 37,5 & 41,43 \\
\hline
\end{tabular}

Como esperado, oberva-se que a viscosidade cinemática do óleo segue a mesma tendência da viscosidade dinâmica, ou seja, diminui com o aumento da temperatura. $\mathrm{O}$ conhecimento dos valores de viscosidade cinemática do óleo residual de frituras é importante para a continuação deste estudo, na qual o óleo será empregado na síntese do biodiesel. Sabese que a qualidade do biodiesel produzido está relacionada com as características da matériaprima oleaginosa utilizada em sua síntese, dentre outros fatores, sendo que a massa específica e a viscosidade cinemática do biodiesel são exemplos de propriedades regulamentadas pela Agência Nacional do Petróleo, Gás Natural e Biocombustíveis (ANP).

\section{CONCLUSÃO}

No presente estudo foram determinadas a massa específica, o comportamento reológico e a viscosidade cinemática de óleo residual de frituras, sujo e filtrado, doméstico recolhido na cidade de Joinville, em diferentes temperaturas. Em todas as temperaturas analisadas $(\mathrm{T}=20$, $25,30,35$ e $40^{\circ} \mathrm{C}$ ), o óleo residual de frituras, nos dois casos, comportou-se como um fluido dilatante, ou seja, sua viscosidade aparente aumenta com o aumento da taxa de deformação. Conforme esperado para líquidos, os valores de massa específica e de viscosidade aparente do óleo diminuíram com o aumento da temperatura.

Na continuação deste trabalho, o óleo residual de frituras será empregado na síntese do biodiesel, e a qualidade do biocombustível obtido está diretamente relacionada com as 


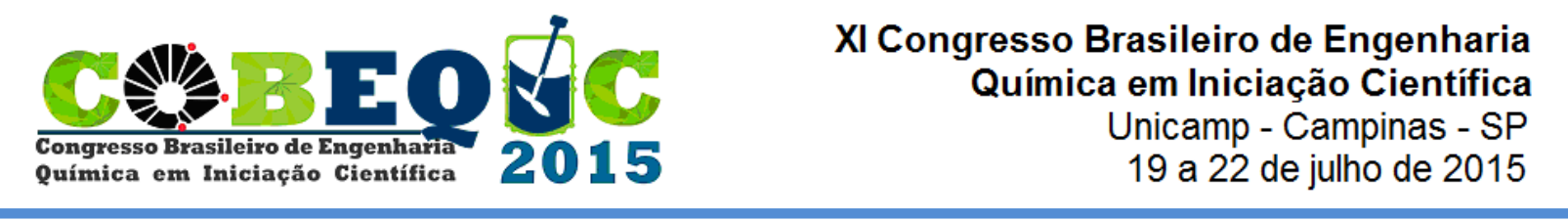

características do óleo empregado na produção. Deste modo, a determinação de propriedades como massa específica e viscosidade cinemática do óleo residual de frituras é necessária, para possibilitar a comparação com estas mesmas propriedades no biodiesel produzido. Tanto a massa específica quanto a viscosidade cinemática do biodiesel são propriedades regulamentadas pela $\mathrm{ANP}$, sendo que o biocombustível não pode ser comercializado caso estas não se enquadrem aos intervalos de valores estabelecidas na regulamentação.

\section{REFERENCIAS}

CARRAPATO, Rita Mafalda Guerreiro. Produção de biodiesel a partir de óleos alimentares usados por via alcalina: o caso de estudo da FCT-UNL. 2010, 128p. Dissertação (Qualificação para Mestrado em Energia e Bioenergia) - Faculdade de Ciências e Tecnologia da Universidade Nova de Lisboa.

CHRISTOFF, P. Produção de biodiesel a partir do óleo residual de fritura comercial. Dissertação (Mestrado em Desenvolvimento de Tecnologias) - Desenvolvimento de Tecnologias, Instituto de Tecnologia para o Desenvolvimento - LACTEC e Instituto de Engenharia do Paraná - IEP, Curitiba, 2006.

COSTA FILHO, E. H. Estudo da produção enzimática de biodiesel utilizando óleo residual e etanol. Dissertação (Mestrado em Engenharia Química) - Departamento de Engenharia Química, Universidade Federal do Ceará, Fortaleza, 2008.

GORREN, R.C.R. Biocombustiveis - Aspectos sociais e econômicos: comparação entre Brasil.

Estados Unidos e Alemanha, 2009, 132p. Dissertação de mestrado - Programa de Pós Graduação em Energia, Universidade de São Paulo.

BORTOLUZZI, O. R. S.; A poluição dos subsolos e águas pelos resíduos de óleo de cozinha. Universidade de Brasília/UEG, Brasília, 2011.

ZHANG, Y.; DUBÉ, M. A.; MCLEAN, D. D.; KATES, M. Biodiesel production from waste cooking oil: 2. Economic assessment and sensitivity analysis. Bioresource technology. v. 90, 229-240, 2003. 